\title{
Inhibition of Hepatic Glycogen Synthesis by Hyperhomocysteinemia Mediated by TRB3
}

\author{
Wen-Jing Liu, ${ }^{*}$ Lan-Qing Ma, ${ }^{\dagger}$ Wei-Hua Liu, ${ }^{*}$ \\ Wei Zhou, ${ }^{*}$ Ke-Qin Zhang, ${ }^{*}$ and Cheng-Gang Zou* \\ From the Laboratory for Conservation and Utilization of \\ Bio-Resources, ${ }^{*}$ Yunnan University, Yunnan; and the \\ Department of Digestive Diseases, ${ }^{\dagger}$ First Affiliated Hospital, \\ Kunming Medical College, Yunnan, China
}

Recently, epidemiological and experimental studies have linked hyperhomocysteinemia (HHcy) to insulin resistance. However, whether HHcy impairs glucose homeostasis by affecting glycogenesis in the liver is not clear. In the present study, we investigated the effect of HHcy on hepatic glycogen synthesis. Hyperhomocysteinemia was induced in mice by drinking water containing two percent methionine. Mice with HHcy showed an increase in the phosphorylation of glycogen synthase and a significant decrease in hepatic glycogen content and the rate of glycogen synthesis. The expression of TRB3 (tribbles-related protein 3) was up-regulated in the liver of mice with HHcy, concomitantly with the dephosphorylation of glycogen synthase kinase- $3 \beta$ and Akt. The knockdown of TRB3 by short hairpin RNA suppressed the dephosphorylation of these two kinases. Homocysteine induced an increase in the levels of hepatic cAMP and cAMP response element-binding protein phosphorylation, which in turn up-regulated the expression of peroxisome proliferator-activated receptor (PPAR)- $\gamma$ coactivator-1 $\alpha$ and TRB3. The inhibition of PPAR- $\alpha$ by its inhibitor, MK886, or knockdown of PPAR- $\alpha$ by small interfering RNA significantly inhibited the expression of TRB 3 induced by homocysteine. The current study demonstrates that HHcy impairs hepatic glycogen synthesis by inducing the expression of TRB3. These results provide a novel explanation for the development and progression of insulin resistance in HHcy. (Am J Pathol 2011, 178: 1489-1499; DOI: 10.1016/j.ajpath.2010.12.052)

The liver is a major organ for glucose metabolism; it maintains blood glucose levels in the fasting condition by production of glucose from intermediates, such as lactate, amino acids, and glycerol, through gluconeogene- sis. ${ }^{1}$ Hepatic gluconeogenesis is controlled by two key enzymes: glucose-6-phosphatase and phosphoenolpyruvate carboxykinase. ${ }^{1}$ In patients with type 2 diabetes mellitus, insulin is less effective in suppressing gluconeogenesis, resulting in increased hepatic glucose output and elevated blood glucose levels. In the liver, in addition to gluconeogenesis, glycogen synthesis and degradation are involved in maintaining blood glucose levels and are dominantly regulated by insulin. If blood glucose levels are high, excess glucose is stored as glycogen, mainly in the liver. ${ }^{2}$ Hepatic glycogen can be broken down to release glucose in times of need. Insulin promotes glycogen accumulation by activation of glycogen synthesis and reduction of glycogen breakdown. The glycogen synthesis and breakdown are controlled by glycogen synthase and glycogen phosphorylase, respectively. Insulin regulates the activities of both enzymes by promoting their dephosphorylation. ${ }^{2}$ Akt plays a critical role in insulin-mediated activation of hepatic glycogen synthase and inactivation of glycogen phosphorylase. $^{3}$

Homocysteine is an intermediate in methionine metabolism. Elevated levels of circulating homocysteine, a condition known as hyperhomocysteinemia (HHcy), are an independent risk factor for atherosclerosis. Epidemiological and experimental studies also link HHcy to insulin resistance. For instance, elevated levels of homocysteine have been observed in a variety of subjects with type 2 diabetes, ${ }^{4}$ metabolic syndrome, ${ }^{5}$ and obesity. ${ }^{6,7}$ On the other hand, HHcy has induced insulin resistance. For

Supported by a grant from the National Natural Science Foundation of China (30560036) and a grant from Yunnan Department of Science and Technology (2009Cl045 to C.-G.Z.).

W.-J.L. and L.-Q.M. contributed equally to this work.

Accepted for publication December 30, 2010.

The authors did not disclose any relevant financial relationships.

Supplemental material for this article can be found at http://ajp. amjpathol.org or at doi:10.1016/j.ajpath.2010.12.052.

Address reprint requests to Cheng-Gang Zou, Ph.D., Laboratory for Conservation and Utilization of Bio-Resources, Yunnan University, No. 2, North Cuihu Road, Kunming, Yunnan 650091, China. E-mail: chgzou@ynu. edu.cn. 
instance, the oral administration of homocysteine induces hyperinsulinemia and promotes the development of insulin resistance in rats. ${ }^{8}$ In contrast, prolonged folate treatment decreases homocysteine and insulin levels, thus improving insulin resistance in patients with metabolic syndrome. ${ }^{9}$ The molecular mechanism by which homocysteine promotes insulin resistance remains unclear. A recent study ${ }^{10}$ has demonstrated that homocysteine upregulates the expression of resistin (a mediator of insulin resistance) and inhibits the phosphorylation of Akt in both primary rat adipocytes and adipose tissue of mice with $\mathrm{HHcy}$. In vitro studies indicate that the oxidative stress produced by homocysteine thiolactone interrupts the insulin signaling pathway by inhibiting the phosphorylation of insulin receptor tyrosine kinase, phosphatidylinositol 3 -kinase, and glycogen synthase kinase $3 \beta$ (GSK3 $\beta$ ) in HTC-IR hepatoma cells. ${ }^{11,12}$

The accumulation of misfolded proteins within the endoplasmic reticulum triggers the activation of an unfolded protein response (UPR). ${ }^{13}$ The UPR leads to transcriptional up-regulation of several target genes, such as 78$\mathrm{kDa}$ glucose-regulated protein and C/EBP homology protein/growth arrest and DNA damage-inducible protein 153 (CHOP). Accumulating evidence suggests that the UPR plays a crucial role in insulin resistance. ${ }^{14,15}$ For instance, activation of the UPR induces the expression of the catalytic subunit of glucose-6-phosphatase (a key gluconeogenic enzyme), leading to an increase in glucose release in primary rat hepatocytes and H4IIE liver cells. ${ }^{16}$ Recent studies have identified that TRB3, a mammalian homologue of Drosophila tribbles (tribbles-related protein 3), ${ }^{17}$ is a target gene of CHOP/ATF4. ${ }^{18,19}$ As a negative modulator of Akt, TRB3 plays an important role in insulin resistance. ${ }^{20}$ Homocysteine has activated the UPR in a variety of cells, including hepatocytes. ${ }^{21,22}$ Thus, it is possible that homocysteine induces insulin resistance by impairing glucose homeostasis through the activation of the UPR pathway. To test this hypothesis, we investigated the effect of HHcy on glycogenesis in the liver. Our results demonstrated that HHcy reduced glycogenesis in the liver by up-regulation of TRB3 expression. However, the induction of TRB3 expression was because of the CAMP-protein kinase A pathway, rather than the UPR pathway.

\section{Material and Methods}

\section{Induction of HHcy}

Twelve-week-old male BALB/c mice were obtained from Yunnan Baiyao Pharmacological Co, Kunming, China. Animals were kept under a constant 12-hour light-dark cycle and were allowed to eat and drink ad libitum. Generally, mild HHcy can be induced by increasing total methionine. ${ }^{23}$ The animals were fed one of the following two diets ${ }^{1}$ : control diet (LM-485 chow; Harlan Teklad, Madison, $\mathrm{WI})^{2}$ or a high-methionine diet (LM-485 chow with drinking water supplemented with two percent L-methionine). Mice were sacrificed after three months on the diets. Homocysteine levels in the plasma of mice were determined by using an enzyme-linked immunosorbent assay kit (Axis-Shield, Dundee, UK). The investigation conforms to the Guide for the Care and Use of Laboratory Animals, published by the US National Institutes of Health. The protocol of the experiments was approved by the Animal Care and Use Committee of Yunnan University, Yunnan, China.

\section{Tissue Glycogen Content}

Animals had ad libitum access to both food and water. Hepatic glycogen concentrations were measured after perchloric acid digestion, as previously described. ${ }^{24}$ Briefly, frozen powder of liver (100 mg to $150 \mathrm{mg}$ ) was extracted with $1.5 \mathrm{~mL}$ of $6 \%(\mathrm{w} / \mathrm{v}) \mathrm{HClO}_{4}$ and centrifuged for 15 minutes at $2000 \times \mathrm{g} ; 0.5 \mathrm{~mL}$ of the supernatant was neutralized with $10 \%(\mathrm{w} / \mathrm{v}) \mathrm{KOH}$. The glycogen in $0.2 \mathrm{~mL}$ of supernatant was hydrolyzed by $\alpha$-amyloglucosidase (50 U/mL; Sigma, St Louis, MO) in sodium acetate buffer $(50 \mathrm{mmol} / \mathrm{L} ; \mathrm{pH}, 4.8)$ overnight at room temperature. The concentration of glycogen in the liver was estimated as the measurement of glucose released from glycogen by a glucose assay kit (Sigma). Hepatic glycogen levels were calculated by determining the difference between the glucose level with and without amyloglucosidase incubation. Glycogen concentration was expressed as glucosyl units (in milligrams) per protein (in grams). The liver was stained with periodic acid-Schiff for glycogen staining.

\section{Measurement of Glycogen Synthesis Rates}

Mice were injected intraperitoneally with tritiated water (2 $\mathrm{mCi} /$ mouse; Atom High-Tech Co, Beijing, China) 2 hours before they were sacrificed. Samples of liver were immediately collected and frozen in liquid nitrogen. The hepatic glycogen synthesis rate in vivo was determined by extracting total glycogen, which includes unlabeled and ${ }^{3} \mathrm{H}$-labeled glycogen, with perchloric acid, as previously described.

\section{Cell Culture and Homocysteine Treatment}

Mouse hepatocytes were isolated as previously described. ${ }^{25}$ Hepatocytes were plated in serum-free William's medium E (Gibco, Gaithersburg, MD), including insulin (20 mU/mL; Sigma) and epidermal growth factor (10 ng/mL; Sigma). ${ }^{26}$ After attachment, the cells were cultured with Dulbecco's modified Eagle's medium (DMEM; Gibco) without serum overnight.

The human hepatocarcinoma cell line HepG2 was obtained from the Kunming Cell Center (Chinese Academy of Sciences, Kunming, China). The cells were grown in DMEM (Gibco) with 10\% fetal bovine serum and maintained at $37^{\circ} \mathrm{C}$ with five percent $\mathrm{CO}_{2}$. When the cells were $60 \%$ to $80 \%$ confluent, the culture medium was changed to DMEM lacking fetal bovine serum and maintained for 24 hours. Experiments were initiated with fresh DMEM with five percent fetal bovine 
Table 1. Primers for Real-Rime PCR

\begin{tabular}{|c|c|c|}
\hline Genes & Sequence & $\begin{array}{l}\text { Product } \\
\text { length } \\
\text { (bp) }\end{array}$ \\
\hline \multicolumn{3}{|l|}{ Mouse } \\
\hline \multicolumn{3}{|l|}{ CHOP } \\
\hline Forward & 5'-TATTGATGCCAAGTGTCCAGTC-3' & 114 \\
\hline Reverse & $5^{\prime}-$ ACAGCAGGTGACAAGTCTGAG-3' & \\
\hline \multicolumn{3}{|c|}{$\begin{array}{l}\text { ATF4 } \\
\text { ATEISE } 5 \text {-ACAGCAGGIGACAAGTLIGAG-3 }\end{array}$} \\
\hline Forward & 5'-TGCCTTTTCCGGGACAGATTG-3' & 124 \\
\hline Reverse & 5'-GTCATCCAACGTGGTCAAGAG-3' & \\
\hline \multicolumn{3}{|c|}{ TRB3 } \\
\hline Forward & 5'-GCAAAGCGGCTGATGTCTG-3' & 77 \\
\hline Reverse & $5^{\prime}$-AGAGTCGTGGAATGGGTATCTG-3' & \\
\hline \multicolumn{3}{|l|}{ GRP78 } \\
\hline Forward & 5'-ACTTGGGGACCACCTATTCCT-3' & 134 \\
\hline Reverse & $5^{\prime}-$ ATCGCCAATCAGACGCTCC $-3^{\prime}$ & \\
\hline \multicolumn{3}{|c|}{$P G C-1 \alpha$} \\
\hline Forward & 5'-TATGGAGTGACATAGAGTGTGCT-3' & 134 \\
\hline Reverse & $5^{\prime}-$ CCACTTCAATCCACCCAGAAAG- $3^{\prime}$ & \\
\hline \multicolumn{3}{|c|}{ PPAR $\alpha$} \\
\hline Forward & $5^{\prime}$-AGAGCCCCATCTGTCCTCTC-3' & 153 \\
\hline Reverse & 5'-ACTGGTAGTCTGCAAAACCAAA-3' & \\
\hline \multicolumn{3}{|c|}{ 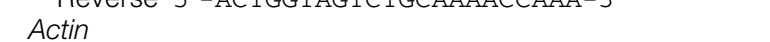 } \\
\hline Forward & 5'-AGTGTGACGTTGACATCCGTA-3' & 112 \\
\hline Reverse & $5^{\prime}-$ GCCAGAGCAGTAATCTCCTTCT-3' & \\
\hline \multicolumn{3}{|c|}{ Human } \\
\hline \multicolumn{3}{|l|}{ TRB3 } \\
\hline Forward & 5'-CTGCCCTACAGGCACTGAGTA-3' & 155 \\
\hline Reverse & $5^{\prime}$-GAGTGAAAAAGGCGTAGAGGAG-3' & \\
\hline \multicolumn{3}{|c|}{ GAPDH } \\
\hline Forward & 5'-ACTTTGGTATCGTGGAAGGACTCA-3' & 133 \\
\hline Reverse & 5'-GTAGAGGCAGGGATGATGTTCTG-3' & \\
\hline
\end{tabular}

GRP, glucose-regulated protein; GAPDH, glyceraldehyde-3-phosphate dehydrogenase.

serum, containing DL-homocysteine (Sigma), unless otherwise indicated.

\section{Quantitative Real-Time RT-PCR Analysis}

Total RNA from cells or liver tissues was isolated using a reagent (TRIzol; Invitrogen, Carlsbad, CA). Randomprimed cDNAs were generated by reverse transcription of total RNA samples with SuperScript II reverse transcriptase (Invitrogen). A real-time PCR analysis was performed with a system (ABI Prism 7000 Sequence Detection System; Applied Biosystems, Foster City, CA) using SYBR Premix-Ex TagTM (Takara Corporation, Dalian, China). The glyceraldehyde-3-phosphate dehydrogenase (for human genes) or $\beta$-actin (for mouse genes) was used for internal control. The primers used for PCR were listed in Table 1.

\section{Western Blotting}

Cells were lysed on ice for 30 minutes in lysis buffer (containing $0.15 \mathrm{~mol} / \mathrm{L} \mathrm{NaCl}, 30 \mathrm{mmol} / \mathrm{L}$ Tris, $1 \mathrm{mmol} / \mathrm{L}$ phenylmethanesulfonyl fluoride, one percent Triton $\mathrm{X}-100,1 \mathrm{mmol} / \mathrm{L}$ EDTA, $10 \mu \mathrm{g} / \mathrm{mL}$ leupeptin, $2 \mu \mathrm{g} / \mathrm{mL}$ pepstatin, $2 \mu \mathrm{g} / \mathrm{mL}$ aprotinin, and $2 \mathrm{mmol} / \mathrm{L} \mathrm{Na}_{3} \mathrm{VO}_{4}$ ). Cell lysates $(25 \mu \mathrm{g})$ of total protein were loaded per well and separated on a $10 \%$ SDS polyacrylamide gel. Proteins were then transferred to polyvinylidene difluoride mem- branes. Primary antibodies were as follows: anti-cAMP response element-binding protein (CREB), anti-phospho (Ser9) CREB, anti-Akt, anti-phospho (Ser473) Akt, antiactin antibodies (1:1000 dilution; Sigma), anti-peroxisome proliferator-activated receptor (PPAR)- $\gamma$ coactivator- $1 \alpha$ (PGC-1 $\alpha)$, anti-PPAR- $\alpha$, anti-phospho (Ser52) elF2 $\alpha$, anti-elF2 $\alpha$, anti-phospho (Ser21) GSK3 $\beta$, and antiGSK3 $\beta$ antibodies (1:1000 dilution; Santa Cruz Biotech, Santa Cruz, CA). The secondary antibody was a peroxidase-coupled anti-rabbit or mouse IgG (1:5000 dilution; Amersham Biosciences, Piscataway, NJ). The membrane was exposed to ECL Hyperfilm (Amersham Biosciences), and the film was developed.

\section{Glucose Tolerance Test}

For glucose tolerance tests, mice fasted overnight. After baseline blood collection, mice were injected intraperitoneally with glucose (2 mg glucose/g body weight). Blood samples were taken from the tail of animals at 20, 40,60, 90 , and 120 minutes after glucose load. The blood glucose concentration was measured (OneTouch Ultra Glucometer; Lifescan, Milpitas, CA). Plasma insulin levels were determined by a radioimmunoassay kit (Linco Research, St Charles, MO).

\section{Plasmid Construction for the Short Hairpin RNA}

To induce stable RNA interference-mediated knockdown of the TRB3 gene, pSilencer2.1-U6 plasmids were constructed to express short hairpin RNAs. Phosphorylated and annealed 64-mer double-stranded DNA oligonucleotides, incorporating BamHI and HindIII restriction sites, were ligated into the respective sites in the pSilencer2.1-U6 vector. The RNA interference sequence was 5'-CGAGCTCGAAGTGGGCCCC-3' for TRB3.

\section{xbp1 mRNA Splicing Assay}

X-box binding protein-1 (xbp1) mRNA splicing was detected as previously described. ${ }^{27}$ In brief, PCR primers, 5'-ACACGCTTGGGAATGGACAC-3' and 5'-CCATGGGAAGATGTTCTGGG-3', encompassing the spliced sequences in xbp1 mRNA were used for PCR amplification with polymerase (TianScript M-MLV; Tiangen Biotech, Beijing, China). The PCR products were separated by electrophoresis on a $2.5 \%$ agarose gel and visualized by ethidium bromide staining.

\section{RNA Interference}

The PPAR- $\alpha$-targeted small interfering RNA (siRNA) (sense, 5' -pGAUCGGAGCUGCAAGAUUCDAdT-3'; antisense, 5'-pGGAUCUUGCAGCUCCGAUCDAdT-3') and the control siRNA targeting the secreted alkaline phosphatase reporter gene (GenBank accession No. U89937) (sense, 5'-pAGGGCAACUUCCAGACCAUDTdT-3'; antisense, 5'-pAUGGUCUGGAAGUUGCCCUDTDT-3' $)^{28}$ were obtained from Takara. The siRNAs were trans- 
A

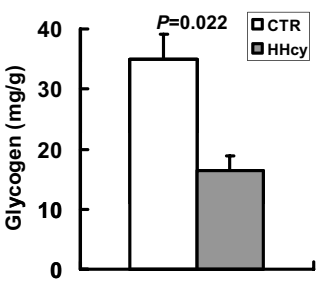

B

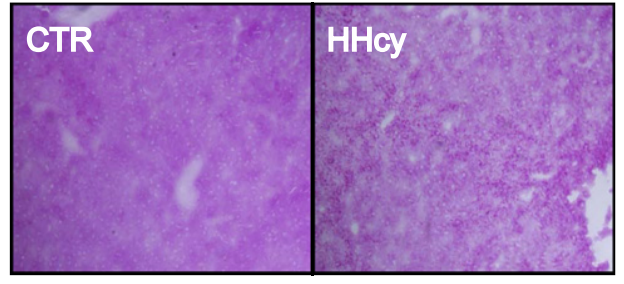

C

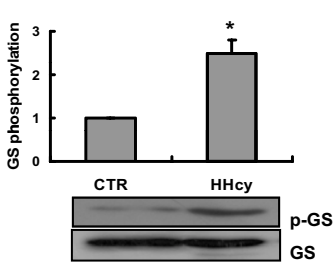

D

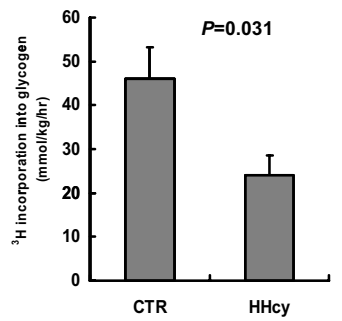

Figure 1. The HHcy impairs glycogen synthesis. Adult BALB/c mice were fed with normal and high-methionine diets. Mice were sacrificed after 3 months. A: Hepatic glycogen content ( $n=9$ in each group). B: Sections of liver with PAS staining. C: Levels of phosphorylated glycogen synthase (GS) were measured using Western blotting analysis. Representative Western blots are shown. ${ }^{*} P<0.05$ versus control (CTR) mice ( $n=5$ in each group). D: Rates of glycogen synthesis were measured after the injection of tritiated water $(2 \mathrm{mCi}$ per mouse).

duced according to the methods previously described. ${ }^{28}$ Briefly, hepatocytes at a density of $5 \times 10^{5}$ cells were transfected with siRNA at a final concentration of $200 \mathrm{nmol} / \mathrm{L}$ using TranslT-siQuest transfection reagent (Mirus Bio Corporation, Madison, WI), according to the manufacturer's protocol. Hepatocytes were harvested 24 hours after transfection, and total RNA or protein was extracted.

\section{Statistical Analysis}

Data from experiments were expressed as the mean \pm $\mathrm{SD}$. The statistical difference between the groups was analyzed using one-way analysis of variance, followed by a Student-Newman-Keuls test. $P<0.05$ was considered statistically significant.

\section{Results}

\section{Hepatic Glycogen Synthesis Is Reduced in HHcy}

In this study, HHcy in mice was induced by drinking water containing two percent methionine. After 3 months on the diet, mice demonstrated an approximately ninefold increase in plasma levels of homocysteine compared with control mice fed a normal diet $(26.5 \pm 2.7$ versus $2.9 \pm 0.4 \mu \mathrm{mol} / \mathrm{L})$. After ad libitum-fed animals were sacrificed, the effect of HHcy on hepatic glycogen con- tent was analyzed. The levels of hepatic glycogen were markedly reduced, with HHcy mice displaying approximately $48 \%$ less glycogen than control mice (Figure 1, A and $\mathrm{B}$ ). The reduced glycogen content in the liver is probably because of an alteration of enzymes involved in glycogenesis. To test this possibility, the phosphorylation levels of glycogen synthase were determined in the liver. The phosphorylation levels of glycogen synthase were significantly increased in the liver from $\mathrm{HHcy}$ mice (Figure 1C), indicating decreased glycogen synthase activity. In the fed state, liver preferentially stores glucose as glycogen. To further study the effect of HHcy on glycogen metabolism, we assessed the rate of glycogenesis in the liver using a tritiated water method. As shown in Figure 1D, glycogenesis in the liver was approximately twofold lower in HHcy mice than in control mice.

\section{HHcy Produces Glucose Intolerance}

The reduction in glycogenic capacity of HHcy mice prompted us to evaluate possible changes in glucose homeostasis. First, we determined blood glucose and plasma insulin levels after a 16-hour fast. Compared with control mice, HHcy mice exhibited significantly increased fasting plasma insulin levels (Figure 2A). In contrast, fasting blood glucose levels in HHcy mice remained unchanged (Figure 2B). Next, we performed a glucose tolerance test in mice, evaluating the ability of the body to adjust glucose levels after an immediate glucose injec-

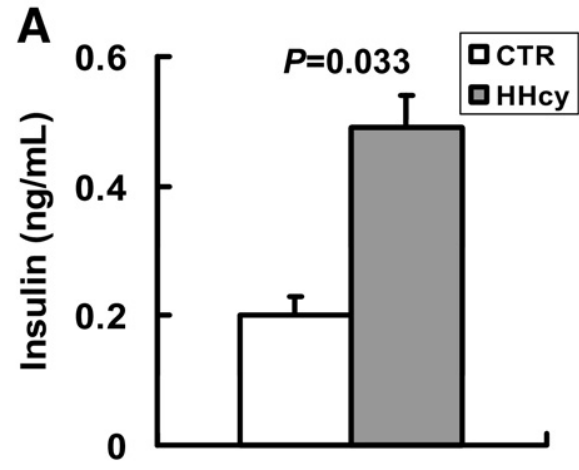

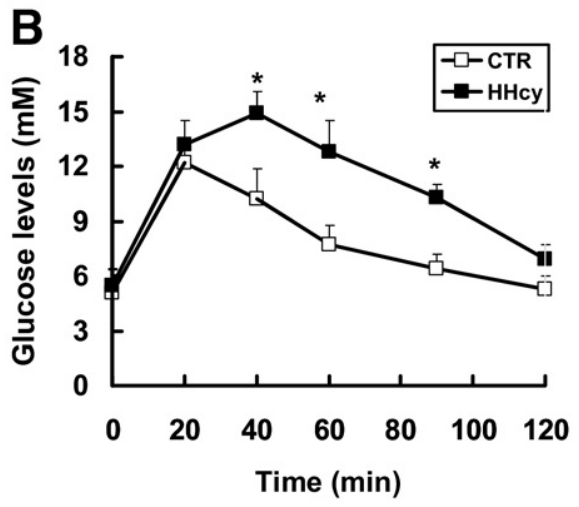

Figure 2. Mice with HHcy display insulin tolerance. A: Fasting plasma levels of insulin were determined by radioimmunoassay ( $n=9$ in each group). B: Blood glucose concentrations during the oral glucose tolerance test in mice with HHcy and control (CTR) mice are shown. ${ }^{*} P<0.05$ versus CTR mice ( $n=7$ in each group). 

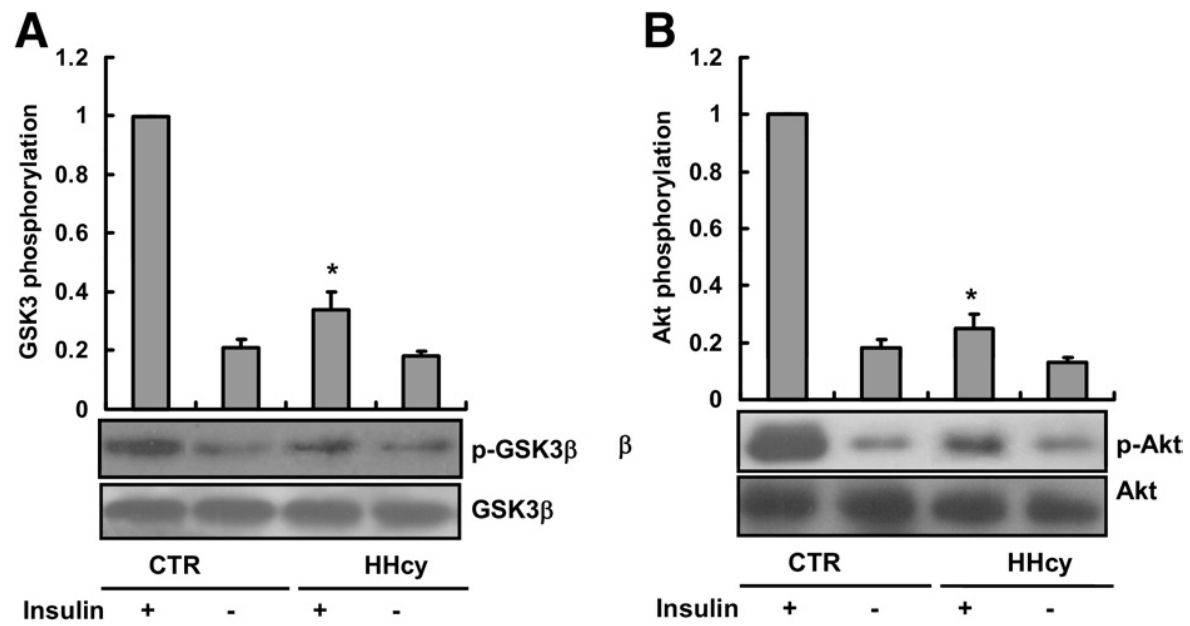

Figure 3. The HHcy inhibits the phosphorylation of GSK $3 \beta$ and Akt. Animals that fasted animals were injected with insulin, and liver tissue was collected at 10 minutes after i.v. injection. Total proteins were extracted from the liver of mice. The levels of phosphorylated GSK3 $\beta$ (A) or Akt (B) were measured using Western blotting analysis. Representative Western blots are shown ${ }^{*} P<0.05$ versus control (CTR) mice ( $n=5$ in each group). tion. When injected i.p. with glucose $(2 \mathrm{~g} / \mathrm{kg})$, the glucose levels of normal mice peaked at 20 minutes and returned to the basal levels at 60 minutes (Figure 2B). In contrast, $\mathrm{HHcy}$ mice showed a delayed response, indicating glucose intolerance.

\section{Homocysteine Inhibits the Phosphorylation of Akt and GSK3 $\beta$}

The GSK3 $\beta$ is a critical component in the regulation of glycogen synthase activity by inducing its phosphorylation. ${ }^{29}$ In insulin-responsive tissue, insulin may inhibit the activity of GSK3 $\beta$ via Akt-mediated phosphorylation of an Ser residue (Ser21). ${ }^{29}$ To determine the effect of $\mathrm{HHcy}$ on the phosphorylation of GSK3 $\beta$ in the liver of mice, animals that fasted were injected with insulin and liver tissue was collected at 10 minutes after intravenous injection. As shown in Figure 3A, the phosphorylation levels of GSK3 $\beta$ (Ser21) in the liver of HHcy mice were lower than those in the liver of control mice. Because GSK3 $\beta$ is a major downstream target of Akt, we also determined the phosphorylation of Akt (Ser473), which results in its activation. On activation, Akt phosphorylates and inactivates GSK3 $\beta .^{30}$ As shown in Figure 3B, the phosphorylation levels of Akt (Ser473) were significantly lower in the liver of HHcy mice.

\section{HHcy Induces Up-Regulation of Hepatic TRB3 Expression}

Previous studies ${ }^{31,32}$ have shown that HHcy induces the UPR in liver, which is responsible for abnormal lipid metabolism. To clarify whether the UPR is involved in HHcy-mediated impairment in glycogen metabolism, we examined the markers of UPR activation in the liver of mice (fed ad libitum). However, neither xbp1 mRNA splicing nor increased elF2 $\alpha$ phosphorylation was observed in the liver of mice with HHcy (see Supplemental Figure S1 at http://ajp.amjpathol.org). Meanwhile, the mRNA levels of ATF4 and the two UPR target genes
(78-kDa glucose-regulated protein and $\mathrm{CHOP}$ ) in HHcy mice were similar to those in normal mice (Figure 4A). In contrast, the mRNA and protein levels of TRB3 were significantly up-regulated in the liver of HHcy mice compared with those in the liver of normal mice (Figure 4, $A$ and $B$ ). Although TRB3 is thought to be a target gene of $\mathrm{CHOP}$ and $\mathrm{ATF} 4,{ }^{18}$ these results suggest that the up-regulation of hepatic TRB3 expression is not because of the UPR in HHcy mice. Furthermore, in vitro studies also demonstrated that homocysteine treatment induced an increase in the mRNA and protein levels of TRB3 in HepG2 cells (Figure 4, C and D).

The TRB3 inhibits insulin signaling by preventing the phosphorylation of $\mathrm{Akt}^{20}$ Thus, the induction of TRB3 is a potential mechanism by which homocysteine could block Akt activation. To further confirm these results, the effect of homocysteine on insulin-induced Akt phosphorylation was determined in HepG2 cells. Serum-starved HepG2 cells were preincubated with 100 $\mu \mathrm{mol} / \mathrm{L}$ homocysteine for 6 hours before stimulation for 10 minutes with $100 \mathrm{nmol} / \mathrm{L}$ insulin. As shown in Figure $4, E$ and $F$, insulin-mediated phosphorylation of Akt (Ser473) and GSK3 $\beta$ (Ser21) was prevented by preincubation with homocysteine. To determine whether the induction of TRB3 was responsible for the inhibition of Akt and GSK3 $\beta$ phosphorylation by homocysteine, we disrupted endogenous TRB3 expression in HepG2 by RNA interference (see Supplemental Figure S2 at $h t t p: / /$ ajp.amjpathol.org). As shown in Figure 4, $E$ and $F$, knockdown of TRB3 by short hairpin RNA blunted the inhibitory effect of homocysteine on the phosphorylation of Akt and GSK3 $\beta$ induced by insulin.

\section{Induction of TRB3 Expression in HHcy Mice Is Mediated by the PGC-1-PPAR- $\alpha$ Pathway}

A previous study ${ }^{33}$ has demonstrated that TRB3 is induced by PGC- $1 \alpha$ through PPAR- $\alpha$ in liver and hepatocytes. The elevated expression of TRB3 has also been observed in skeletal muscle of PGC- $1 \alpha$-transgenic mice. ${ }^{34}$ Thus, we determined the effect of HHcy 

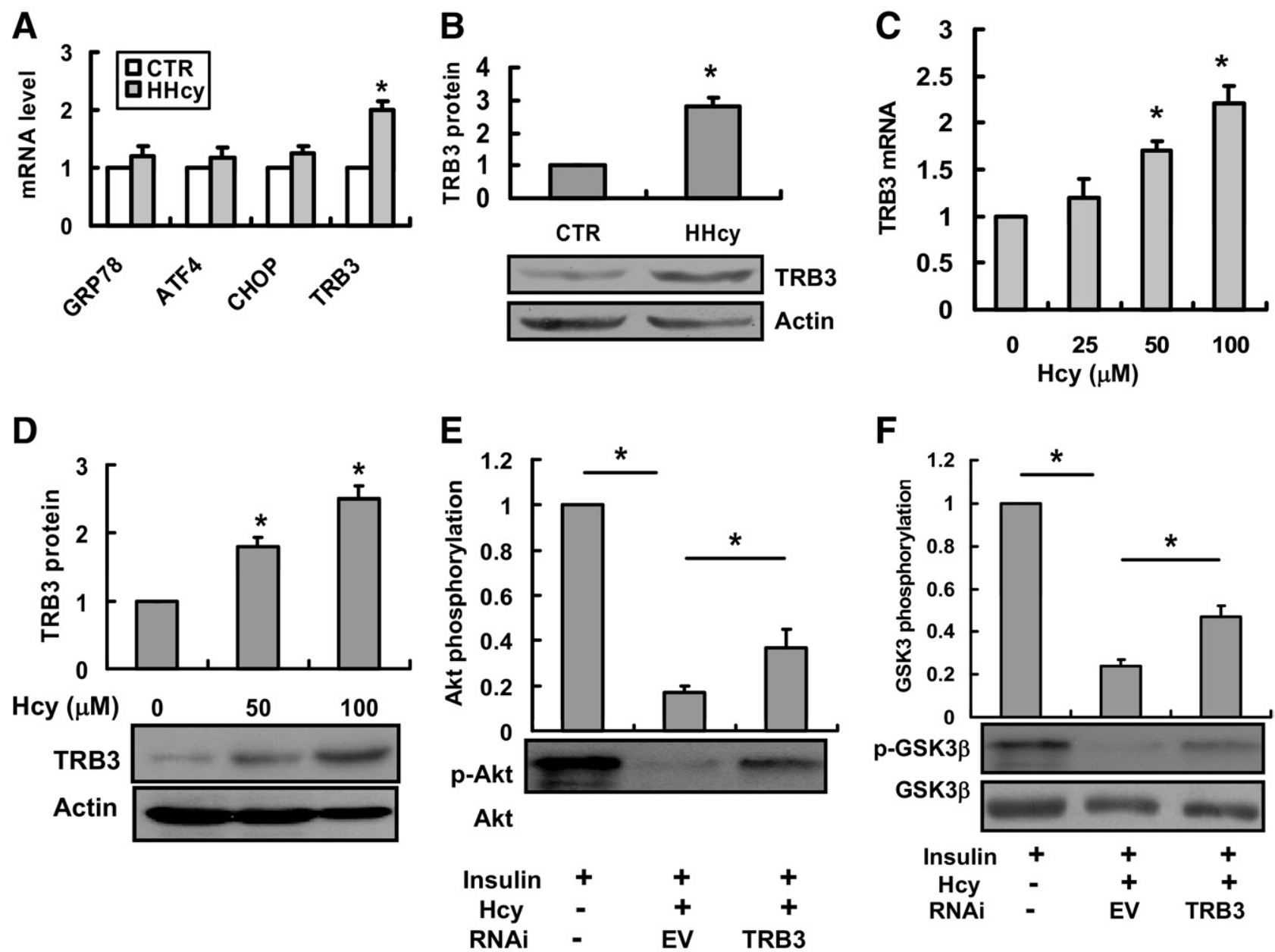

Figure 4. The TRB3 expression is up-regulated in mice with HHcy. A: Total RNA was extracted from the liver of mice. The mRNA levels were detected by real-time PCR. All results are standardized to the levels of $\beta$-actin and are the mean $\pm \mathrm{SD}(n=9$ in each group). B: The levels of TRB3 proteins were measured using Western blotting analysis. Representative Western blots are shown. ${ }^{*} P<0.05$ versus control (CTR) mice ( $n=5$ in each group). C: HepG2 cells were incubated with 0 to $100 \mu \mathrm{mol} / \mathrm{L}$ homocysteine (Hcy) for 6 hours. Total RNA was extracted and subjected to real-time PCR. All results are standardized to the levels of glyceraldehyde3-phosphate dehydrogenase and are the mean \pm SD of five experiments. ${ }^{*} P<0.05$ versus CTR (without Hcy). D: The protein levels of TRB3 were measured using Western blotting analysis. Representative Western blots are shown. ${ }^{*} P<0.05$ versus CTR (with Hcy) ( $n=5$ in each group). Stable cell lines of HepG 2 that express short hairpin RNA for the TRB3 gene were produced by transfection of pSilencer2.1-U6-short hairpin RNA, followed by positive colony selection using G418. Serum-starved cells were preincubated with Hcy $(100 \mu \mathrm{mol} / \mathrm{L})$ for 6 hours before incubation with insulin $(100 \mathrm{nmol} / \mathrm{L})$ for $10 \mathrm{minutes}$. Whole cell proteins were extracted and analyzed by Western blotting. E: The Akt analysis. F: The GSK3 $\beta$ analysis. Representative Western blots are shown. ${ }^{*} P<0.05$. EV indicates empty vector.

on the expression of PGC- $1 \alpha$ and PPAR- $\alpha$. As shown in Figure 5, $A$ and $B$, the mRNA and protein levels of PGC- $1 \alpha$ were significantly up-regulated in the liver of HHcy mice. Furthermore, homocysteine treatment also induced the mRNA and protein levels of PGC-1 $\alpha$ in mouse primary cultured hepatocytes (Figure 5, C and D). However, the mRNA and protein levels of PPAR- $\alpha$ in the liver of HHcy mice were similar to those in the liver of control mice (Figure 5, A and B). To test the role of PPAR- $\alpha$ in the induction of TRB3 expression, primary cultured hepatocytes were pretreated with an inhibitor of PPAR- $\alpha$, MK886. ${ }^{35}$ As shown in Figure 6, A and B, MK886 (50 $\mu \mathrm{mol} / \mathrm{L})$ significantly inhibited the expression of TRB3 induced by homocysteine. In addition, we disrupted endogenous PPAR- $\alpha$ expression in primary cultured hepatocytes by siRNA (see Supplemental Figure S3 at http://ajp.amjpathol.org). We found that knockdown of PPAR- $\alpha$ by siRNA attenuated the ex- pression of TRB3 induced by homocysteine (Figure 6, $\mathrm{C}$ and D).

\section{HHcy Activates the CAMP-CREB Pathway}

The expression of PGC- $1 \alpha$ is strongly induced by CAMP in primary cultures of hepatocytes. ${ }^{36}$ In this study, we found that both the levels of hepatic cAMP (Figure 7A) and the phosphorylation of CREB were markedly higher in HHcy mice than control mice (Figure 7B). Homocysteine treatment also induced the phosphorylation of CREB in hepatocytes (Figure 7C). These results are consistent with observations from Woo et al. ${ }^{37}$ As expected, pretreatment with H89 (5 $\mu \mathrm{mol} / \mathrm{L}$ ) (a specific inhibitor of protein kinase $A$ ) or adenylyl cyclase toxin (100 $\mu \mathrm{mol} / \mathrm{L}$ ) (a specific inhibitor of adenylyl cyclase) markedly suppressed the effect of the phosphorylation of CREB in hepatocytes (Figure 

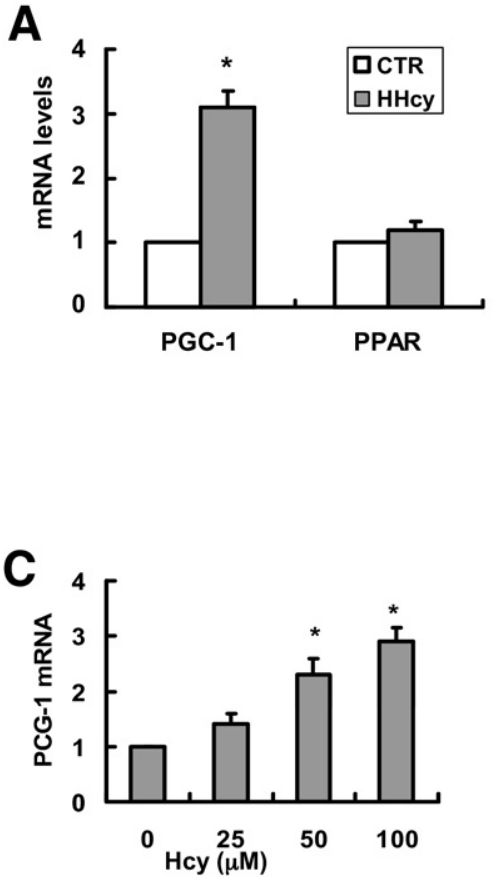

B

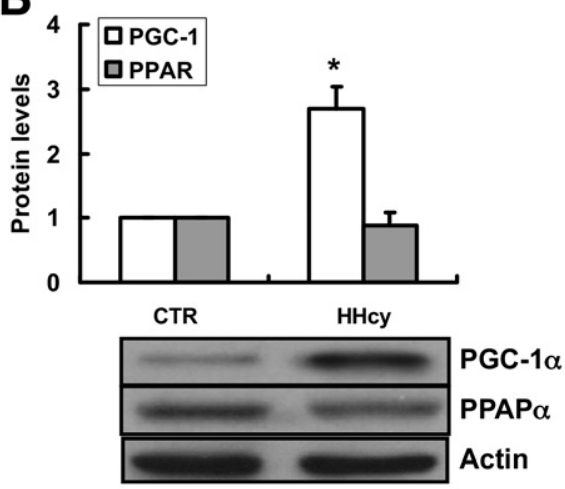

D

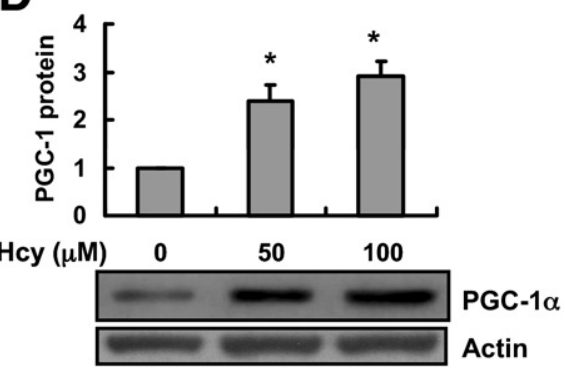

Figure 5. The expression of PGC- $1 \alpha$ is upregulated in mice with HHcy. A: Total RNA was extracted from the liver of mice. The mRNA levels were detected by real-time PCR. All results are standardized to the levels of $\beta$-actin and are the mean $\pm \mathrm{SD}(n=6$ in each group). ${ }^{*} P<0.05$ versus control (CTR) B: The levels of proteins were measured using Western blotting analysis. Representative Western blots are shown. ${ }^{*} P<0.05$ versus CTR $(n=6)$. C: Primary cultured hepatocytes were incubated with 0 to 100 $\mu \mathrm{mol} / \mathrm{L}$ homocysteine (Hcy) for 6 hours. Total RNA was extracted and subjected to realtime PCR. All results are standardized to the levels of $\beta$-actin and are the mean $\pm \mathrm{SD}$ of five experiments. ${ }^{*} P<0.05$ versus CTR (without Hcy). D: The levels of proteins were measured using Western blotting analysis. Representative Western blots are shown. ${ }^{*} P<0.05$ versus CTR (without Hcy) $(n=5)$.
7C). To determine whether the cAMP-CREB pathway is responsible for the induction of $\mathrm{PGC}-1$ and TRB3 expression by homocysteine, hepatocytes were preincubated with $\mathrm{H} 89$ or adenylyl cyclase toxin. As shown in Figure 7, D-F, H89 and adenylyl cyclase toxin attenuated the expression of PGC-1 and TRB3 induced by homocysteine. These data suggest that the elevation of hepatic cAMP levels is involved in the induction of PGC-1 and TRB3 expression in mice with HHcy.
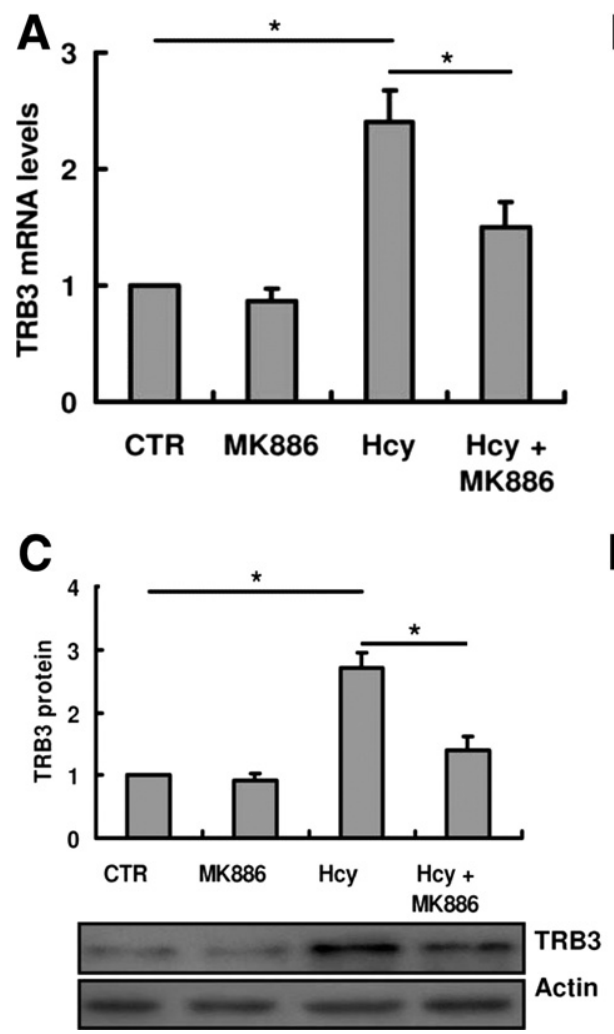

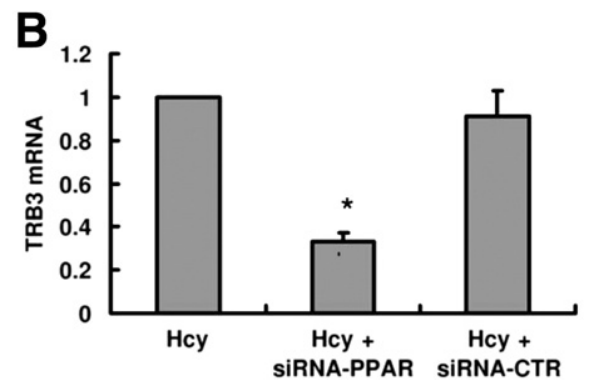

D

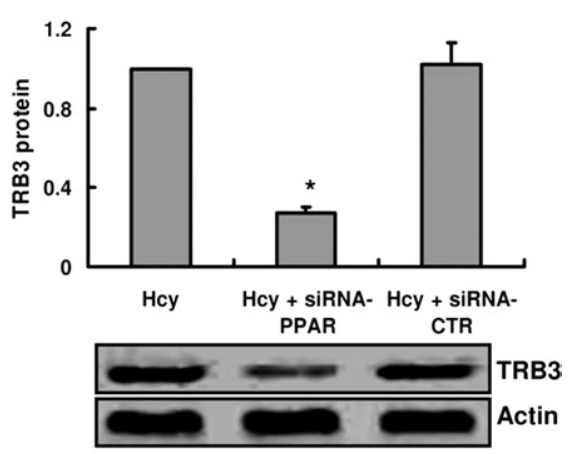

Figure 6. Induction of TRB3 expression by homocysteine is PPAR- $\alpha$ dependent. Primary cultured hepatocytes were preincubated with MK886 (50 $\mu \mathrm{mol} / \mathrm{L})$ for $30 \mathrm{~min}$ utes after treatment with homocysteine (100 $\mu \mathrm{mol} / \mathrm{L}$ ) (Hcy) for 6 hours. A: Total RNA was extracted and subjected to real-time PCR. All results are standardized to the levels of $\beta$-actin and are the mean \pm SD of five experiments. B: The levels of proteins were measured using Western blotting analysis. Representative Western blots are shown $(n=5) .{ }^{*} P<0.05$ between Hcy and control, and between Hcy and Hcy+MK886. Hepatocytes were transfected with siRNA against PPAR- $\alpha$ or the CTR siRNA. After treatment with Hcy $(100 \mu \mathrm{mol} / \mathrm{L})$ for 6 hours, total RNA $(\mathbf{C})$ or protein $(\mathbf{D})$ was extracted. ${ }^{*} P<$ 0.05 versus Hcy. 
A

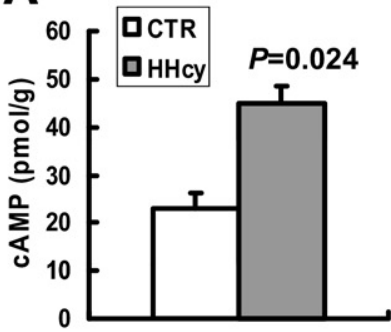

D

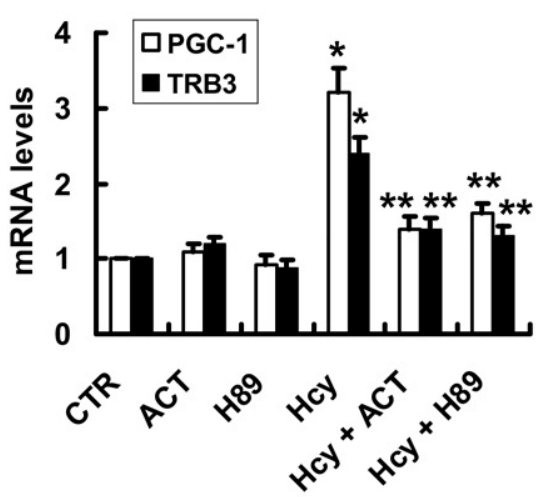

B

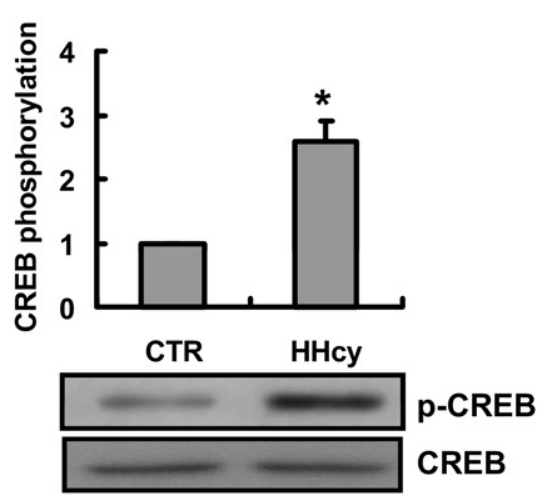

E

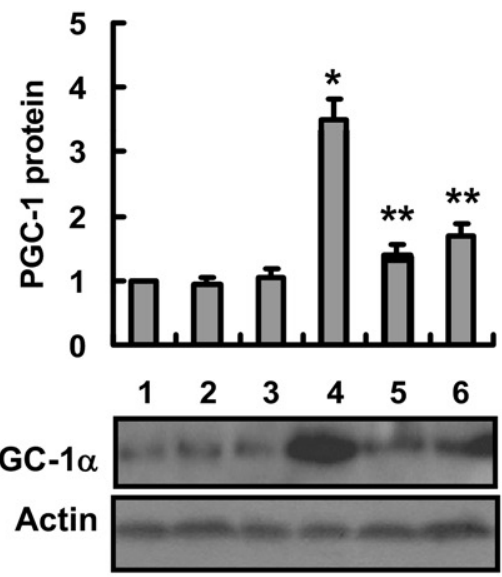

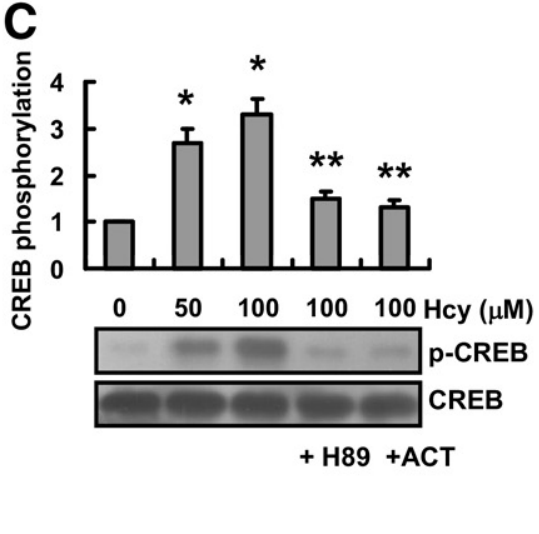

$\mathbf{F}$

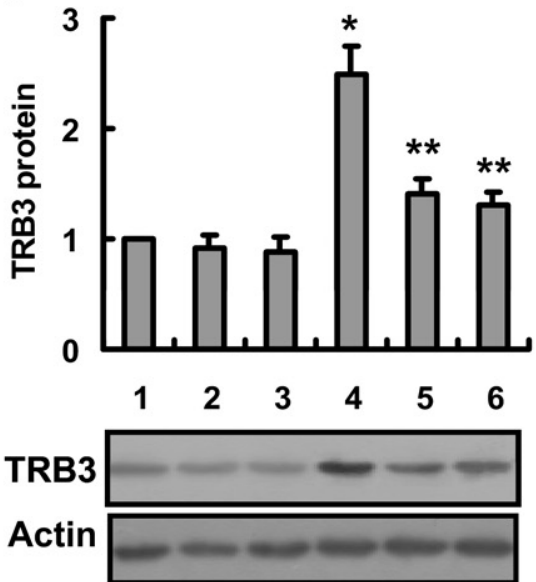

Figure 7. Up-regulation of TRB3 is mediated by the cAMP-CREB pathway as the result of inhibition of Akt by homocysteine. A: Hepatic cAMP levels were measured using an enzyme-linked immunosorbent assay. Results are expressed as mean + SD ( $n=9$ in each group). B: The levels of phosphorylated CREB were measured using Western blotting analysis. Representative Western blots are shown. ${ }^{*} P<0.05$ versus control (CTR) $(n=5)$. HHcy indicates hyperhomocysteinemia. C: Primary cultured hepatocytes were preincubated with $100 \mu \mathrm{mol} / \mathrm{L}$ adenylyl cyclase toxin (ACT) or $5 \mu$ mol/L H89 for 30 minutes After incubation with homocysteine (Hcy) for 3 hours, the levels of phosphorylated CREB were measured using Western blotting analysis. Representative Western blots are shown $(n=4)$. D: Hepatocytes were preincubated with $100 \mu \mathrm{mol} / \mathrm{L}$ ACT or $5 \mu$ mol/L H89 for 30 minutes. Then, the cells were incubated with Hcy for 6 hours. Total RNA was extracted and subjected to real-time PCR. All results are standardized to the levels of $\beta$-actin and are the mean + SD Western blots are shown $(n=5)$. Lane 1 , CTR; lane 2, ACT; lane 3, H89; lane 4, Hcy; lane 5, Hcy + ACT; lane 6, Hcy + H89. ${ }^{*} P<0.05$ versus CTR; ${ }^{* *} P<0.05$ versus Hcy.

\section{Discussion}

Although in vivo and in vitro studies $8,9,11,12$ suggest that homocysteine causes insulin resistance, the mechanisms of homocysteine-induced insulin resistance are incompletely understood. In the present study, we found that the fasting basal levels of serum insulin were elevated twofold in HHcy mice, suggesting compensatory hypersecretion due to peripheral insulin resistance. ${ }^{38}$ Meanwhile, glucose tolerance test results demonstrated that glucose tolerance was impaired in HHcy mice, indicating lowered insulin sensitivity. The development of progressive glucose intolerance in $\mathrm{HHcy}$ mice may result from a reduction of glycogen in liver. To test this hypothesis, we studied the impact of homocysteine on glycogen metabolism. The hepatic glycogen content and the rate of glycogen synthesis were significantly lower in HHcy mice and were reduced by approximately $40 \%$ to $50 \%$ relative to normal mice. Moreover, HHcy mice exhibited an increase in the phosphorylation of glycogen synthase in the liver from HHcy mice, reflecting a decrease in glycogen synthase activity. In liver, the main consequence of insulin resistance is unrestrained hepatic glucose production; underlying mechanisms include decreased glycogen synthesis and failure to suppress gluconeogenesis. ${ }^{39}$ Thus, HHcy induces insulin resistance, at least in part, by impairing the synthesis of hepatic glycogen.

The elevations of homocysteine cause activation of the UPR in the liver of mice. ${ }^{31,32}$ Because the activation of UPR has been involved in insulin resistance, ${ }^{14,15}$ we first tested whether the effect of homocysteine on glycogen metabolism is the result of activation of the UPR. However, xbp1 mRNA splicing, the phosphorylation of elF2 $\alpha$, and the expression of $78-\mathrm{kDa}$ glucose-regulated protein and $\mathrm{CHOP}$ did not significantly change in the liver of HHcy mice, which had an eightfold elevation in plasma levels of homocysteine. Recently, Gupta et $\mathrm{al}^{40}$ reported that even cystathionine beta-synthase-deficient mice with a mean serum homocysteine concentration of $169 \mu \mathrm{mol} / \mathrm{L}$ do not exhibit the activation of the UPR. These results suggest that the UPR, per se, 
is unlikely to play a role in the inhibitory effect of HHcy on glycogen synthesis. Interestingly, a significant increase in the expression of TRB3 was observed in the liver of HHcy mice or HepG2 cells after homocysteine treatment. Although TRB3 has been the target of CHOP and ATF4, ${ }^{18} \mathrm{a}$ direct causal role for CHOP and ATF4 mediating the upregulation of TRB3 expression in mice with $\mathrm{HHcy}$ is excluded.

The phosphatidylinositol 3-kinase-Akt pathway plays a central role in regulating glucose transport, gluconeogenesis, and glycogen synthesis. ${ }^{41}$ In vitro studies ${ }^{11,12}$ have demonstrated that homocysteine thiolactone disrupts insulin signaling by inhibiting insulin-stimulated phosphatidylinositol 3-kinase activity and phosphorylation of GSK $3 \beta$ and glycogen synthesis in HTC hepatoma cells. We observed that the phosphorylation of Akt in the liver was significantly lower in HHcy mice than in control mice. The GSK3 $\beta$ is a major downstream target of Akt, which can phosphorylate GSK3 $\beta$ to make it inactive. ${ }^{42}$ In this study, our results also demonstrated that the phosphorylation levels of GSK3 $\beta$ were dramatically decreased in the liver of HHcy mice. The GSK3 $\beta$ can phosphorylate and thereby inactivate glycogen synthase, resulting in reduced glycogenesis. ${ }^{42}$ Thus, dephosphorylation of GSK3 $\beta$ by homocysteine may explain the inhibitory effect on glycogen synthesis. The TRB3 has interacted directly with Akt and suppressed the phosphorylation of this kinase in liver. ${ }^{20}$ In this study, knockdown of TRB3 by short hairpin RNA suppressed the inhibitory effect of homocysteine on the phosphorylation of Akt and GSK3 $\beta$ in HepG2. Thus, TRB3 is probably a critical component in the glycogen metabolism disorders mediated by homocysteine. Interestingly, reduced activity of Akt by inducing the expression of TRB3 is also observed in hepatic tissues in rats fed long-term with ethanol. ${ }^{43}$ It is well established that long-term ethanol consumption leads to a marked decrease in hepatic glycogen content, which is related to a depressed rate of synthesis. ${ }^{44,45} \mathrm{Be}$ cause mild HHcy (10 to $30 \mu \mathrm{mol} / \mathrm{L}$ ) is common in alcoholics, ${ }^{46}$ reduced hepatic glycogen by long-term ethanol consumption is probably associated with HHcy.

Elevated phosphorylation levels of CREB and protein kinase $A$ activities in the liver of HHcy mice have been previously reported. ${ }^{37}$ Our results demonstrated that the levels of intracellular CAMP and CREB phosphorylation were increased in the liver of HHcy mice. Both H89 and adenylyl cyclase toxin significantly suppressed homocysteine-induced CREB phosphorylation in hepatocytes. Both in vivo and in vitro studies ${ }^{33}$ indicate that PPAR- $\alpha$ promotes TRB3 expression in liver and hepatocytes in a PGC- $1 \alpha$-dependent manner. Because CREB is the main positive regulator of PGC- $1 \alpha$ expression in liver, ${ }^{36,47}$ the up-regulation of TRB3 expression induced by homocysteine is probably mediated by the PGC- $1 \alpha-$ PPAR- $\alpha$ pathway. To test this hypothesis, we determined the effect of homocysteine on the expression of PGC- $1 \alpha$. In the liver of HHcy mice, the mRNA and protein levels of PGC- $1 \alpha$, rather than PPAR- $\alpha$, were markedly elevated. Homocysteine treatment (25 to 100 $\mu \mathrm{mol} / \mathrm{L})$ also resulted in an increase in the expression of PGC- $1 \alpha$ in hepatocytes but did not alter the expression of

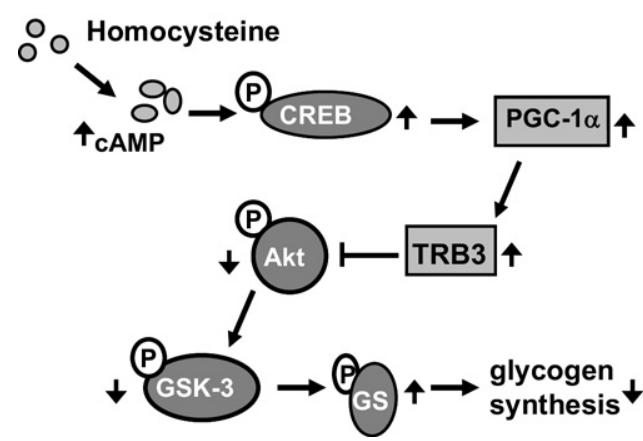

Figure 8. The proposed mechanism of homocysteine-induced inhibition of hepatic glycogen synthesis. Homocysteine induces an increase in the intracellular levels of cAMP and the phosphorylation (P) of CREB in hepatocytes. Activation of this pathway promotes the expression of PGC$1 \alpha$, which, in turn, up-regulates the expression of TBR3. The TRB3 inhibits the phosphorylation of Akt and GSK $3 \beta$. The GSK $3 \beta$ induces the phosphorylation of glycogen synthase (GS), leading to reduced glycogen synthesis.

PPAR- $\alpha$ (data not shown). However, both the PPAR- $\alpha$ inhibitor MK886 and knockdown of PPAR- $\alpha$ by siRNA significantly suppressed the homocysteine-mediated up-regulation of TRB3 in hepatocytes. The PGC- $1 \alpha-$ PPAR- $\alpha$ pathway is located downstream of CREB. Our results demonstrated that the inhibition of CREB phosphorylation by H89 (5 $\mu \mathrm{mol} / \mathrm{L})$ or adenylyl cyclase toxin attenuated the expression of PGC- $1 \alpha$ and TRB3. Taken together, these data suggest that the CAMP-CREB-PGC- $1 \alpha-$ PPAR- $\alpha$ pathway probably plays a critical role in homocysteine-induced expression of TRB3 in liver.

Based on the data presented herein and on previously published data, we propose the following scheme by which HHcy inhibits glycogen synthesis in liver (Figure 8). Homocysteine elicits the levels of intracellular CAMP and CREB phosphorylation, which, in turn, induces the expression of PGC- $1 \alpha$, leading to up-regulation of TRB3 expression. The TRB3 inhibits the phosphorylation of Akt and GSK $3 \beta$, leading to increased phosphorylation levels of glycogen synthase and reduced hepatic glycogen synthesis. Our study expands our view of the role of HHcy in insulin resistance.

\section{Acknowledgments}

We thank Dr. Jian-Guo Wu, Ph.D. (Wuhan University, Wuhan, China), for providing the pSilencer2.1-U6 plasmids; and Dr. Yu-Chen Xie, M.D. (The Second People's Hospital of Yunnan, Kunming, China), for her technical help in glycogen staining.

\section{References}

1. Barthel A, Schmoll D: Novel concepts in insulin regulation of hepatic gluconeogenesis. Am J Physiol Endocrinol Metab 2003, 285 : E685-E692

2. Bollen M, Keppens S, Stalmans W: Specific features of glycogen metabolism in the liver. Biochem J 1998, 336(Pt 1):19-31

3. Aiston S, Hampson LJ, Arden C, Iynedjian PB, Agius L: The role of protein kinase B/Akt in insulin-induced inactivation of phosphorylase in rat hepatocytes. Diabetologia 2006, 49:174-182

4. Emoto M, Kanda H, Shoji T, Kawagishi T, Komatsu M, Mori K, Tahara $H$, Ishimura $E$, Inaba $M$, Okuno $Y$, Nishizawa $Y$ : Impact of insulin 
resistance and nephropathy on homocysteine in type 2 diabetes. Diabetes Care 2001, 24:533-538

5. Meigs JB, Jacques PF, Selhub J, Singer DE, Nathan DM, Rifai N, D'Agostino RB Sr, Wilson PW: Fasting plasma homocysteine levels in the insulin resistance syndrome: the Framingham offspring study. Diabetes Care 2001, 24:1403-1410

6. De Pergola G, Pannacciulli N, Zamboni M, Minenna A, Brocco G, Sciaraffia M, Bosello, Giorgino R: Homocysteine plasma levels are independently associated with insulin resistance in normal weight, overweight and obese pre-menopausal women. Diabetes Nutr Metab 2001, 14:253-258

7. Fonseca VA, Fink LM, Kern PA: Insulin sensitivity and plasma homocysteine concentrations in non-diabetic obese and normal weight subjects. Atherosclerosis 2003, 167:105-109

8. Golbahar J, Aminzadeh MA, Kassab SE, Omrani GR: Hyperhomocysteinemia induces insulin resistance in male Sprague-Dawley rats. Diabetes Res Clin Pract 2007, 76:1-5

9. Setola E, Monti LD, Galluccio E, Palloshi A, Fragasso G, Paroni R, Magni F, Sandoli EP, Lucotti P, Costa S, Fermo I, Galli-Kienle M, Origgi A, Margonato A, Piatti $P$ : Insulin resistance and endothelial function are improved after folate and vitamin B12 therapy in patients with metabolic syndrome: relationship between homocysteine levels and hyperinsulinemia. Eur J Endocrinol 2004, 151:483-489

10. Li Y, Jiang C, Xu G, Wang N, Zhu Y, Tang C, Wang X: Homocysteine upregulates resistin production from adipocytes in vivo and in vitro. Diabetes 2008, 57:817-827

11. Najib S, Sanchez-Margalet V: Homocysteine thiolactone inhibits insulin signaling, and glutathione has a protective effect. J Mol Endocrinol 2001, 27:85-91

12. Najib S, Sanchez-Margalet V: Homocysteine thiolactone inhibits insulin-stimulated DNA and protein synthesis: possible role of mitogenactivated protein kinase (MAPK), glycogen synthase kinase-3 (GSK-3) and p70 S6K phosphorylation. J Mol Endocrinol 2005, 34: $119-126$

13. Ron D, Walter $P$ : Signal integration in the endoplasmic reticulum unfolded protein response. Nat Rev Mol Cell Biol 2007, 8:519-529

14. Boden G, Duan X, Homko C, Molina EJ, Song W, Perez O, Cheung P, Merali S: Increase in endoplasmic reticulum stress-related proteins and genes in adipose tissue of obese, insulin-resistant individuals. Diabetes 2008, 57:2438-2444

15. Eizirik DL, Cardozo AK, Cnop M: The role for endoplasmic reticulum stress in diabetes mellitus. Endocr Rev 2008, 29:42-61

16. Wang D, Wei Y, Schmoll D, Maclean KN, Pagliassotti MJ: Endoplasmic reticulum stress increases glucose-6-phosphatase and glucose cycling in liver cells. Endocrinology 2006, 147:350-358

17. Mata J, Curado S, Ephrussi A, Rorth P: Tribbles coordinates mitosis and morphogenesis in Drosophila by regulating string/CDC25 proteolysis. Cell 2000, 101:511-522

18. Ohoka N, Yoshii S, Hattori T, Onozaki K, Hayashi H: TRB3, a novel ER stress-inducible gene, is induced via ATF4-CHOP pathway and is involved in cell death. EMBO J 2005, 24:1243-1255

19. Zou CG, Cao XZ, Zhao YS, Gao SY, Li SD, Liu XY, Zhang Y, Zhang $K Q$ : The molecular mechanism of endoplasmic reticulum stress-induced apoptosis in PC-12 neuronal cells: the protective effect of insulin-like growth factor I. Endocrinology 2009, 150:277-285

20. Du K, Herzig S, Kulkarni RN, Montminy M: TRB3: a tribbles homolog that inhibits Akt/PKB activation by insulin in liver. Science 2003, 300:1574-1577

21. Outinen PA, Sood SK, Pfeifer SI, Pamidi S, Podor TJ, Li J, Weitz J, Austin RC: Homocysteine-induced endoplasmic reticulum stress and growth arrest leads to specific changes in gene expression in human vascular endothelial cells. Blood 1999, 94:959-967

22. Zhang C, Cai Y, Adachi MT, Oshiro S, Aso T, Kaufman RJ, Kitajima S: Homocysteine induces programmed cell death in human vascular endothelial cells through activation of the unfolded protein response. J Biol Chem 2001, 276:35867-35874

23. Dayal S, Lentz SR: Murine models of hyperhomocysteinemia and their vascular phenotypes. Arterioscler Thromb Vasc Biol 2008 28:1596-1605

24. Postle AD, Bloxham DP: The use of tritiated water to measure absolute rates of hepatic glycogen synthesis. Biochem J 1980, 192:65-73

25. Vitvitsky V, Dayal S, Stabler S, Zhou Y, Wang H, Lentz SR, Banerjee $\mathrm{R}$ : Perturbations in homocysteine-linked redox homeostasis in a mu- rine model for hyperhomocysteinemia. Am J Physiol Regul Integr Comp Physiol 2004, 287:R39-R46

26. Hansen LK, Albrecht JH: Regulation of the hepatocyte cell cycle by type I collagen matrix: role of cyclin D1. J Cell Sci 1999, 112(Pt 17):2971-2981

27. Lisbona F, Rojas-Rivera D, Thielen P, Zamorano S, Todd D, Martinon F, Glavic A, Kress C, Lin JH, Walter P, Reed JC, Glimcher LH, Hetz C: BAX inhibitor-1 is a negative regulator of the ER stress sensor IRE1alpha. Mol Cell 2009, 33:679-691

28. De Souza AT, Dai X, Spencer AG, Reppen T, Menzie A, Roesch PL, He Y, Caguyong MJ, Bloomer S, Herweijer H, Wolff JA, Hagstrom JE, Lewis DL, Linsley PS, Ulrich RG: Transcriptional and phenotypic comparisons of Ppara knockout and siRNA knockdown mice. Nucleic Acids Res 2006, 34:4486-4494

29. Brady MJ, Saltiel AR: The role of protein phosphatase-1 in insulin action. Recent Prog Horm Res 2001, 56:157-173

30. Patel S, Doble B, Woodgett JR: Glycogen synthase kinase-3 in insulin and Wnt signalling: a double-edged sword? Biochem Soc Trans 2004, 32:803-808

31. Werstuck GH, Lentz SR, Dayal S, Hossain GS, Sood SK, Shi YY, Zhou J, Maeda N, Krisans SK, Malinow MR, Austin RC: Homocysteineinduced endoplasmic reticulum stress causes dysregulation of the cholesterol and triglyceride biosynthetic pathways. J Clin Invest 2001, 107:1263-1273

32. Namekata K, Enokido Y, Ishii I, Nagai $Y$, Harada T, Kimura H: Abnormal lipid metabolism in cystathionine beta-synthase-deficient mice, an animal model for hyperhomocysteinemia. J Biol Chem 2004, 279 : 52961-52969

33. Koo SH, Satoh H, Herzig S, Lee CH, Hedrick S, Kulkarni R, Evans RM, Olefsky J, Montminy M: PGC-1 promotes insulin resistance in liver through PPAR-alpha-dependent induction of TRB-3. Nat Med 2004 10:530-534

34. Choi CS, Befroy DE, Codella R, Kim S, Reznick RM, Hwang YJ, Liu ZX, Lee HY, Distefano A, Samuel VT, Zhang D, Cline GW, Handschin C, Lin J, Petersen KF, Spiegelman BM, Shulman GI: Paradoxica effects of increased expression of PGC-1alpha on muscle mitochondrial function and insulin-stimulated muscle glucose metabolism. Proc Natl Acad Sci U S A 2008, 105:19926-19931

35. Kehrer JP, Biswal SS, La E, Thuillier P, Datta K, Fischer SM, Vanden Heuvel JP: Inhibition of peroxisome-proliferator-activated receptor (PPAR)alpha by MK886. Biochem J 2001, 356:899-906

36. Yoon JC, Puigserver P, Chen G, Donovan J, Wu Z, Rhee J, Adelmant G, Stafford J, Kahn CR, Granner DK, Newgard CB, Spiegelman BM: Control of hepatic gluconeogenesis through the transcriptional coactivator PGC-1. Nature 2001, 413:131-138

37. Woo CW, Siow YL, O K: Homocysteine activates cAMP-response element binding protein in HepG2 through cAMP/PKA signaling pathway. Arterioscler Thromb Vasc Biol 2006, 26:1043-1050

38. Crosson SM, Khan A, Printen J, Pessin JE, Saltiel AR: PTG gene deletion causes impaired glycogen synthesis and developmental insulin resistance. J Clin Invest 2003, 111:1423-1432

39. Leclercq IA, Da Silva Morais A, Schroyen B, Van Hul N, Geerts A: Insulin resistance in hepatocytes and sinusoidal liver cells: mechanisms and consequences. J Hepatol 2007, 47:142-156

40. Gupta S, Kuhnisch J, Mustafa A, Lhotak S, Schlachterman A, Slifker MJ, Klein-Szanto A, High KA, Austin RC, Kruger WD: Mouse models of cystathionine beta-synthase deficiency reveal significant threshold effects of hyperhomocysteinemia. FASEB J 2009, 23:883-893

41. Farese RV, Sajan MP, Standaert ML: Insulin-sensitive protein kinases (atypical protein kinase $\mathrm{C}$ and protein kinase B/Akt): actions and defects in obesity and type II diabetes. Exp Biol Med (Maywood) 2005, 230:593-605

42. Cross DA, Watt PW, Shaw M, van der Kaay J, Downes CP, Holder JC, Cohen $P$ : Insulin activates protein kinase $B$, inhibits glycogen synthase kinase-3 and activates glycogen synthase by rapamycin-insensitive pathways in skeletal muscle and adipose tissue. FEBS Lett 1997, 406:211-215

43. He L, Simmen FA, Mehendale HM, Ronis MJ, Badger TM: Chronic ethanol intake impairs insulin signaling in rats by disrupting Akt association with the cell membrane: role of TRB3 in inhibition of Akt/protein kinase B activation. J Biol Chem 2006, 281 : 11126-11134 
44. Winston GW, Reitz RC: Chronic ethanol ingestion and glycogen metabolism in male and female rats. Adv Exp Med Biol 1980, 132:569-577

45. Van Horn CG, Ivester P, Cunningham CC: Chronic ethanol consumption and liver glycogen synthesis. Arch Biochem Biophys 2001, 392 $145-152$
46. Lentz SR, Haynes WG: Homocysteine: is it a clinically important cardiovascular risk factor? Cleve Clin J Med 2004, 71:729-734

47. Herzig S, Long F, Jhala US, Hedrick S, Quinn R, Bauer A, Rudolph D, Schutz G, Yoon C, Puigserver P, Spiegelman B, Montminy M: CREB regulates hepatic gluconeogenesis through the coactivator PGC-1. Nature 2001, 413:179-183 